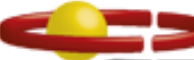 \\ 10日E: : \\ Centro Universitárı de Brasílıa \\ CENTRO UNIVERSITÁRIO DE BRASÍLIA - UnICEUB \\ PROGRAMA DE INICIAÇÃO CIENTÍFICA
}

GABRIELA GONÇALVES NUNES

GUILHERME FEITOSA DO NASCIMENTO

EFEITO DE ÓLEOS ESSENCIAIS SOBRE A GERMINAÇÃO DE CONÍDIOS E CRESCIMENTO MICELIAL DE FUNGO DA ANTRACNOSE - Colletotrichum acutatum

BRASÍLIA 


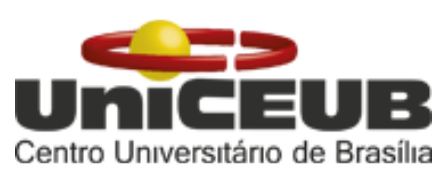

GABRIELA GONÇALVES NUNES

GUILHERME FEITOSA DO NASCIMENTO

EFEITO DE ÓLEOS ESSENCIAIS SOBRE A GERMINAÇÃO DE CONÍDIOS E CRESCIMENTO MICELIAL DE FUNGO DA ANTRACNOSE - Colletotrichum acutatum

Relatório final de pesquisa de Iniciação Científica apresentado à Assessoria de Pós-Graduação e Pesquisa.

Orientação: Lélia Cristina Tenório Leoi Romeiro

BRASÍLIA

2018 
Ao Centro Universitário de Brasília - UniCEUB pela oportunidade de desenvolver este projeto de iniciação científica (PIC);

A Professora Lélia Cristina Tenório Leoi Romeiro, por ter aceitado participar deste projeto, pela orientação, paciência, por seus valiosos ensinamentos e por seu apoio e confiança;

Aos funcionários do LABOCIEN, em especial ao Douglas William dos Prazeres Sousa pelo auxílio durante todo o experimento, por sua dedicação, presteza, gentileza, por todo empenho e disposição em colaborar com o projeto;

Aos nossos queridos amigos Jessika Veridiano, Rafael de Jesus, Lucas Morais por todo apoio, ajuda e incentivo nos momentos mais difíceis, pelos momentos de descontração e alegria.

Ao amigo Luíz Henrique que nos doou os isolados do fungo, oriundos de sua pesquisa, pertencentes a coleção da Embrapa Hortaliças.

Agradecemos a Deus que nos deu forças para chegar até o fim apesar de todos os desafios e adversidades. 


\title{
RESUMO
}

\section{EFEITO DE ÓLEOS ESSENCIAIS SOBRE A GERMINAÇÃO DE CONÍDIOS E CRESCIMENTO MICELIAL DE FUNGO DA ANTRACNOSE- Colletotrichum}

\author{
acutatum.
}

Dentre as frutas produzidas no Brasil encontram-se o morango (Fragaria $s p$.$) , um$ pseudofruto com produção anual estimada em 105 mil toneladas, tendo como principais produtores os estados de Minas Gerais, Rio Grande do Sul e São Paulo. O cultivo do morango expandiu para diferentes tipos de climas e solos até sua chegada ao Distrito Federal. Das diversas doenças do morangueiro encontra-se a Antracnose, causada pelo fungo do gênero Colletotrichum spp. Essa doença típica e agressiva manifesta-se principalmente pelo sintoma denominado flor-preta, causando sérios prejuízos para a localidades produtoras de morango, pois ataca diretamente as flores e frutos, provocando grande queda na produção. Atualmente a principal estratégia de controle deste fungo pelos produtores é o uso químico de substância com efeito fungicida sobre a cultura. Indo na direção oposta, temos um aumento na procura de produtos naturais e orgânicos pela sociedade brasileira, seguindo inclusive uma tendência mundial. Diante disso, várias pesquisas estão tendo como foco principal o desenvolvimento de metodologias de controle de doenças que sejam menos agressivos ao meio ambiente, e nesta circunstância o estudo do uso de óleos essenciais tem se mostrado como uma boa alternativa. O objetivo no presente estudo foi extrair e avaliar o efeito de cinco óleos essenciais em diferentes concentrações, com propriedades antimicrobianas sobre o crescimento micelial e germinação de conídios, das plantas capim limão (Cymbopogon citratus Staph), citronela (Cymbopogon nardus (L.) Rendle.), manjericão (Ocimum basilicumL.), tomilho (Thymus vulgarisL.), sálvia (Salvia officinalis L.). A metodologia utilizada para extração dos óleos essenciais foi por hidrodestilação utilizando o aparelho tipo Clevenger, e para a contagem de conídios foi utilizada a Câmara de Neubauer. Para avaliar o efeito dos óleos essenciais no crescimento micelial, esporulação e germinação de esporos do fungo foram utilizadas alíquotas de 5, 10, 15,20 e $25 \mu \mathrm{L}$ do óleo essencial, e estas foram distribuídas na superfície do meio de cultura BDA contido em placas de Petri antes da repicagem do fungo. Das cinco espécies de plantas utilizadas para a extração do óleo essencial, em apenas duas (capim-limão e citronela) as quantidades de óleo extraídas foram suficientes para a realização dos experimentos delineados. Para fim de comparação de eficiência foi utilizado uma testemunha e um fungicida comercial (sulfato de cobre). As alíquotas a partir de $15 \mu \mathrm{L}$ inibiram em mais de $60 \%$ a germinação e a produção dos esporos isolados quando comparados com a testemunha, e mais eficientes, inclusive, que o fungicida. Nos estudos, o óleo essencial do capim-limão mostrou-se mais efetivo do que o óleo de citronela. Diante disso, os óleos essenciais revelam-se uma propícia alternativa para o desenvolvimento de tratamentos fitossanitários para o uso de doenças em plantas, dentre elas o morangueiro.

Palavras-Chave: Antracnose. morango. Colletotrichum acutatum. óleo essencial.

\section{Sumário}




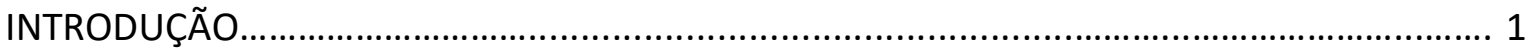

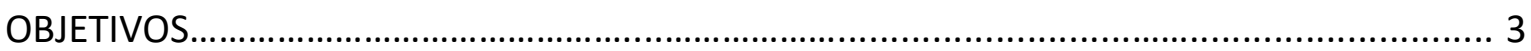

JUSTIFICATIVA

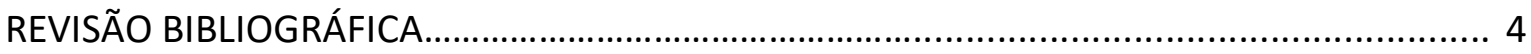

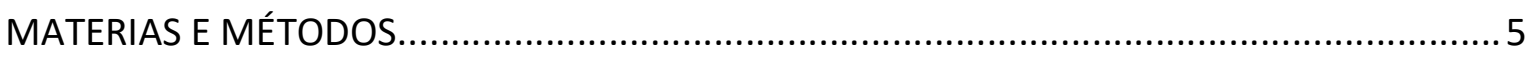

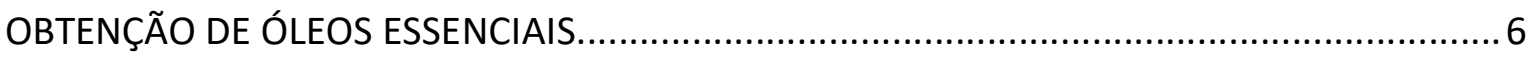

OBTENÇÃO DO INÓCULO DE Colletotrichum acutatum.................................................. 6

EFEITO IN VITRO DOS ÓLEOS ESSENCIAIS SOBRE A GERMINAÇÃO DE CONÍDIOS E CRESCIMENTO MICELIAL DE Colletotrichum acutatum................................................. 7

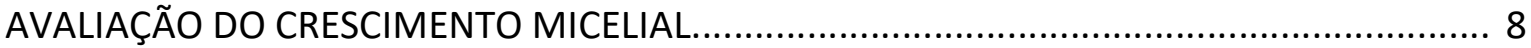

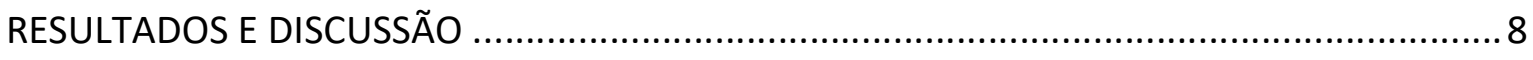

CONCLUSÃO

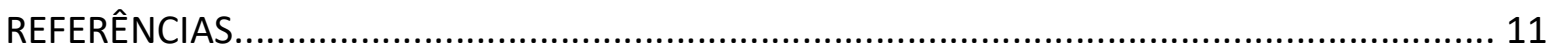




\section{INTRODUÇÃO}

Entre os maiores países produtores de frutas, destacam-se respectivamente a China, a Índia e o Brasil, juntos geram o equivalente a $43,6 \%$ da produção mundial, sendo as suas produções destinadas principalmente aos seus mercados internos (BRASIL, 2015).

Em 2015, o Brasil colheu aproximadamente 41,0 milhões de toneladas de frutas, destas, apenas $2 \%$ eram destinadas ao mercado externo, o restante voltado para o mercado interno para consumo in-natura ou processada. (TREICHEL et al, 2016).

Dentre as frutas produzidas no Brasil, encontram-se o morango (Fragaria sp.), um pseudofruto com produção anual estimada em 105 mil toneladas, sendo as Minas Gerais, o Rio Grande do Sul e São Paulo, os principais estados produtores. Nas últimas décadas, o cultivo expandiu para diferentes tipos de climas e solos até sua chegada ao Distrito Federal (DF) (VIGNOLO et al. 2014).

Segundo o pesquisador Henz (2010), no Distrito Federal a inserção da cultura de morango obteve sucesso em razão da altitude da região e das condições climáticas. Ainda de acordo com ele, as altas temperaturas que ocorrem no verão seguido de um inverno ameno e seco, favorecem de forma positiva para floração, a frutificação e a qualidade dos frutos (HENZ, 2010).

Dentre as cidades-satélites que compõem o Distrito Federal, destaca-se Brazlândia como grande produtora desse cultivar, desempenhando um importante papel na agricultura familiar dessa região (GOMES et al., 2013).

Um dos problemas determinantes na cultura de morango e de outras cultivares de importância no DF é a ocorrência de doenças que variam na sua forma e fases em que aparecem no ciclo do vegetal, podendo atacar desde as sementes até os frutos. As infestações mais recorrentes são causadas por fungos (TANAKA et al., 2005; SIMON et al., 2005).

Das diversas doenças do morangueiro encontra-se a Antracnose, causada pelo fungo do gênero Colletotrichum spp. Essa doença típica e agressiva manifesta-se principalmente pelo sintoma denominado flor-preta, causando sérios prejuízos para a localidades 
produtoras de morango, pois ataca diretamente as flores e frutos, provocando grande queda na produção. É a doença de maior incidência nos cultivos de morangueiro no Brasil e no DF, causando danos durante todo o ciclo, com perdas de até $50 \%$ da produção (FRANCO e BETTIOL, 2000).

Atualmente a principal estratégia de controle deste fungo pelos produtores é o uso químico de substância com efeito fungicida sobre a cultura. Indo na direção oposta, temos um aumento na procura de produtos naturais e orgânicos pela sociedade brasileira, seguindo inclusive uma tendência mundial (CRUZ et al., 2015). Diante disso, várias pesquisas estão tendo como foco principal o desenvolvimento de metodologias de controle de doenças que sejam menos agressivos ao meio ambiente, e nesta circunstância o estudo do uso de óleos essenciais tem se mostrado como uma boa alternativa. Diversas pesquisas apontam a atividade fungitóxica de óleos essenciais extraídos de plantas por meio de diversas técnicas, tais como arraste e hidrodestilação (MORAIS et al., 2009; CRUZ et al., 2015).

Óleos essenciais são caracterizados quimicamente como misturas complexas de compostos secundários de baixo peso molecular. São sintetizados pelos vegetais para sua proteção e sobrevivência, sendo alguns altamente voláteis em temperatura ambiente. Não se misturam com a água, apresentam um aspecto oleoso e geralmente são extraídos de parte de plantas como frutas, flores, cascas, folhas ou de plantas inteiras (WOLFFENBÜTTEL, 2007).

As atividades antimicrobianas dos óleos essenciais dependem diretamente das concentrações utilizadas, porém as concentrações mínimas inibitórias (CMI) variam conforme alguns fatores, tais como o potencial do óleo extraído da planta; pela variação no quimiótipo causada por diferenças geográficas entre as plantas coletadas; idade da planta; método de extração do óleo essencial; método utilizado para acessar a atividade antifúngica; local da extração na planta; entre outros fatores (MAIA et al,2015).

Portanto, o presente trabalho pretende avaliar o potencial de ação de diferentes óleos essenciais sobre o crescimento micelial e germinação de conídios de Colletotrichum 
acutatum, isolados de cultivares do morangueiro (Fragaria vesca L.) e discutir os efeitos e possibilidades para o manejo deste fitopatógeno.

Assim sendo, o presente trabalho teve por objetivo extrair e avaliar o efeito de cinco óleos essenciais em diferentes concentrações, com propriedades antimicrobianas sobre o crescimento micelial e germinação de conídios de Colletotrichum spp, das plantas capim limão (Cymbopogon citratus Staph), citronela (Cymbopogon nardus (L.) Rendle.), manjericão (Ocimum basilicum L.), tomilho (Thymus vulgaris L.), sálvia (Salvia officinalis L.).

\section{OBJETIVOS}

\subsection{GERAIS}

Avaliar o efeito de óleos essenciais em diferentes concentrações extraídos das plantas: capim limão (Cymbopogon citratus Staph), citronela (Cymbopogon nardus(L.) Rendle.), manjericão (Ocimum basilicum L.), tomilho (Thymus vulgaris L.), sálvia (Salvia officinalis L.) no tratamento do fungo Colletotrichum acutatum, causador da doença antracnose que acomete diversas culturas, dentre elas o morangueiro.

\subsection{ESPECÍFICOS}

- Extrair óleos essenciais das plantas capim limão, citronela, manjericão, tomilho e sálvia, através de métodos de hidrodestilação de diferentes partes foliar das respectivas plantas;

- Testar diferentes concentrações dos óleos essenciais extraídos de diferentes espécies no controle de Colletotrichum acutatum;

- Comparar a eficiência fungicida dos óleos essenciais extraídos das diferentes espécies de plantas com fungicida comercial vendido em Lojas destinadas à jardinagem;

- Apresentar um método alternativo no controle da antracnose para diminuição dos efeitos de perda na produção de cultivares, principalmente as do morango, no DF.

\section{JUSTIFICATIVA}

Propiciar o melhoramento no cultivo do morango, visto que é uma das grandes cultivares de importância socioeconômica de Brasília, sendo a cidade-satélite de Brazlândia maior produtora de morango do Centro-Oeste. 
Uma das finalidades principais do uso de óleos essenciais está na diminuição direta do uso de produtos químicos no combate de fungos no cultivo do morango, impactando diretamente nos custos do produto para os agricultores, bem como no aumento da qualidade do produto final para os consumidores.

Os óleos essenciais são benéficos por serem produtos cuja matéria prima é abundante na natureza e por eles se mostrarem eficientes em diversos tratamentos por suas propriedades antifúngicas e antibacterianas, uma alternativa para reduzir o tratamento com produtos agrotóxicos, pois sua aplicação é menos onerosa, o benefício é significativo e não causa prejuízos ao meio ambiente, visando assim um importante papel no controle de fitopatógenos (SOUSA, 2012).

Algumas medidas de controle da antracnose são aplicadas atualmente pelos produtores, tais como a rotação de culturas, o tratamento de sementes e o uso de mudas sadias. Essas medidas adotadas visam minimizar a incidência de contaminação, pois mudas infectada são a principal causa de introdução do patógeno em áreas isentas da doença, o manejo adequado do solo, eliminação de órgãos doentes como folhas, flores e frutos, bem como o controle da irrigação devem ser feitos de forma criteriosa, pois a alta umidade favorece a disseminação do patógeno e a consequentemente diminuição da qualidade e quantidade dos morangos produzidos (CAFÉ FILHO et al. 2001).

O tratamento químico com fungicidas (dosagem em gramas de ingrediente ativo/ 100 L de água), como por exemplo o captan (120 g) e o folpet (135 g), são produtos preventivos registrados que tem apresentado maior eficácia no controle dessa doença, esses fungicidas podem ser aplicados alternadamente 1 ou 2 vezes por semana, conforme a severidade da doença, porém, ambos os fungicidas são com relação à proteção do meio ambiente considerados Classe III, ou seja, perigosos ao meio ambiente. (UENO,1996).

\section{REVISÃO BIBLIOGRÁFICA}

A antracnose é uma doença que se inicia por meio da germinação dos conídios seguida da produção de apressórios, estruturas que liberam enzimas como cutinases, celulases, pectinases, para viabilizar a entrada das hifas nos tecidos intactos. Dessa maneira, as hifas podem penetrar os tecidos por meio dos estômatos, ferimentos que foram causados por 
insetos, lesão com deformação superficial sem ruptura da epiderme ou por fatores climáticos. A disseminação pode ocorrer, se a curtas distâncias através do transporte de conídios por meio do vento e chuva; a longa distância a doença pode ser carregada pelas sementes ou por órgãos da planta infectada (SILVA et al., 2014).

O capim-limão (Cymbopogon citratus) tem como principal substância o citral chegando a representar de 65 a $85 \%$ dos compostos presentes. É uma mistura de isômeros geranial (isômero trans, $\alpha$-citral) e neral (isômero cis, $\beta$-citral). Além deste composto, o óleo dessa planta também possui quantidades relevantes de $\beta$-mirceno e geraniol, apresentando também isoorientina, isoscoparina, sweria japonina, isoorientina 2-O-ramnosídeo, orientina, ácido clorogênico, ácido caféico. O extrato de capim-limão ou seus compostos específicos, citral, $\beta$-mirceno e geraniol, tem apresentado ótimas atividades antioxidantes, observadas por testes in vitro e in vivo (VILLAVERDE et al., 2013).

Manjericão (Ocimum basilicum) espécie vegetal que pertence à família Lamiaceae possui propriedades de inseticida e fungicida no controle de fitopatógenos (MORAIS; CASTANHA, 2012). De acordo com Simões e Spitzer (1999), “A composição química do óleo essencial do manjericão apresenta grande quantidade de compostos secundários, bem como de marcadores, o que confere a existência de diferentes quimiotipos".

Sálvia (Salvia officinalis) possui propriedade antioxidante e sua caracterização química quanto à atividade antimicrobiana contra vários microrganismos tem sido reconhecida há décadas e tem sido atribuída à presença de alguns compostos principais no óleo essencial, como 1,8-cineol, $\beta$-thuyona, cânfora, borneol e p-cimeno, entre outros. Seu óleo essencial tem se mostrado também eficaz contra várias bactérias, por exemplo, Listeria monocytogenes, Bacillus cereus, Bacillus subtilis, Escherichia coli e Staphylococcus aureus (PIEROZAN e tal.,2009).

O Tomilho (Thymus vulgaris L.) é uma planta aromática, condimentar e medicinal, pertencente à família Lamiaceae. A atividade biológica do óleo essencial de tomilho está associada com o timol e o carvacrol, seus principais constituintes. O timol possui significativos efeitos antibacterianos, antifúngicos e anti-helmínticos, enquanto o carvacrol tem sido estudado por apresentar efeitos bactericidas (ROCHA et al.,2012). 
A Citronela (Cymbopogon winterianum Jowitt) possui um óleo que é extraído de suas folhas por ser rico em aldeído citronelal (cerca de 40\%) tendo pequenas quantidades de geraniol, citronelol e ésteres. A substância, citronelol, apresenta uma excelência como aromatizante e repelente de insetos, ademais apresenta ação antimicrobiana local e acaricida (MATTOS, 2000).

\section{MATERIAIS E MÉTODOS}

Os experimentos foram realizados nos Laboratórios LABOCIEN do Centro Universitário de Brasília - UniCEUB, Brasília, DF, no período de agosto de 2017 a agosto de 2018. Foram utilizadas para a extração de óleo essencial cinco tipos de plantas (capim-limão, citronela, sálvia, tomilho e manjericão), e dos óleos essenciais obtidos em quantidade e qualidade suficiente foram os utilizados para realizar os experimentos. Os diferentes isolados do fungo Colletotrichum spp. foram obtidos por meio da coleção da Embrapa (HORTALIÇAS).

\subsection{OBTENÇÃO DE ÓLEOS ESSENCIAIS}

As plantas utilizadas na obtenção dos óleos essenciais foram cultivadas no espaço destinado à pesquisa do UniCEUB. O critério utilizado para a escolha das espécies foi baseado no potencial de controle que os seus óleos essenciais apresentaram em outros patossistemas. (Tabela 1).

Tabela 1. Nome comum e científico das plantas avaliadas para a extração dos óleos essenciais.

\begin{tabular}{|c|c|}
\hline Nome comum & Nome científico \\
\hline Manjericão & Ocimum basilicum $L$. \\
\hline Capim-limão & Cymbopogon citratus Staph \\
\hline Sálvia & Salvia officinalis $L$. \\
\hline Tomilho & Thymus vulgaris $L$. \\
\hline Citronela & Cymbopogon nardus (L.) Rendle \\
\hline
\end{tabular}

Para o procedimento da extração dos óleos essenciais foi utilizados material foliar (jovem e maduro), todos frescos de cada espécie. As folhas foram coletadas no período do 
final da tarde até a noite (entre $18 \mathrm{~h}$ e $19 \mathrm{~h}$ ), posteriormente as mesmas foram cortadas em pequenos pedaços e pesadas $150 \mathrm{~g}$ de material foliar em um béquer.

Para cada extração foram utilizadas todas as folhas da planta, ou seja, conforme a produção foliar de cada espécie, por isso foi estabelecido um padrão de $150 \mathrm{~g}$, a amostra de material vegetal fresco foi adicionada $500 \mathrm{~mL}$ de água destilada dentro do balão de fundo redondo $(1000 \mathrm{~L})$, posteriormente o material foi submetido ao processo de hidrodestilação, no aparelho graduado de Clevenger, todo o procedimento durou em média 3 horas. Os óleos essenciais foram extraídos e na sequência separados do hidrolato por decantação e secos por meio de percolação em $\mathrm{Na}_{2} \mathrm{SO}_{4}$ anidro. Foi realizado o cálculo de rendimento dos óleos essenciais a partir da massa do material ( fresco) e a massa do óleo extraído. Ao final foram identificados, protegidos da luz e armazenados à $4^{\circ} \mathrm{C}$ em vidro âmbar até sua utilização.

Das cinco plantas (capim-limão, citronela, sálvia, tomilho e manjericão) que foram usadas para a extração do óleo essencial, em apenas duas obteve êxito em quantidade e qualidade de óleo para a realização de todos os experimentos propostos, sendo elas: capimlimão e a citronela. Diante disso, as demais plantas foram desconsideradas dos experimentos de propriedades antimicrobianas no crescimento micelial e na germinação de conídios de Colletotrichum spp.

\subsection{OBTENÇÃO DO INÓCULO DE Colletotrichum acutatum.}

Os isolados do fungo Colletotrichum acutatum mais comum em morango foram obtidos por meio da coleção da Embrapa, dois deles, isolado 645 e isolado 754 foram selecionados aleatoriamente para o experimento. Para a recuperação do isolado realizou-se repicagem do mesmo em placas de Petri com meio de cultura Agar Batata Dextrose - BDA. As placas foram acondicionadas em estufa a $25^{\circ} \mathrm{C}$, com fotoperíodo.

\subsection{EFEITO IN VITRO DOS ÓLEOS ESSENCIAIS SOBRE A GERMINAÇÃO DE CONÍDIOS E CRESCIMENTO MICELIAL DE Colletotrichum acutatum.}


Para avaliação do efeito dos óleos sobre a germinação dos conídios foram testados dois óleos essenciais: citronela e capim-limão nas seguintes concentrações (em $\mu \mathrm{L}$ ) 5; 10; 15; 20 e 25.

Após o crescimento dos dois isolados em placas BDA, adicionou-se $10 \mathrm{~mL}$ de água destilada autoclavada em cada placa, em seguida a superfície de cada colônia foi raspada utilizando-se a alça de drigalski. Após a raspagem, cada amostra foi filtrada com auxílio de gazes e com auxílio de um funil pequeno, o filtrado foi depositado em um béquer identificado, limpo e autoclavado.

Para cada delineamento experimental foram preparados sete tubos de microcentrífuga de $2 \mathrm{~mL}$ (tipo eppendorf), sendo assim distribuídos: tubo 01 testemunha, tubos 02 a 06 com óleo essencial distribuídos em concentrações diferentes, e no tubo 07 o fungicida sulfato de cobre (dimy).

Ao total foram dois isolados (645 e 754) e dois óleos essenciais (capim-limão e citronela). Portanto, foram usados o isolado 645 com os óleos essenciais capim-limão e citronela, e isolado 754 com os óleos essenciais capim-limão e citronela. Em cada combinação (isolado x óleo essencial) foram utilizados sete tubos de microcentrífuga com 2 $\mathrm{mL}$ de filtrado obtido de cada isolado. $\mathrm{O}$ tubo 01 de cada delineamento foi marcado como testemunha, os tubos de 2 a 6 foram adicionados os respectivos óleo-essenciais nas concentrações (5; 10; 15; 20 e $25 \mu \mathrm{L}$ ), e no tubo 07 foi adicionado o fungicida (10\%). Foram realizados três repetições para cada delineamento.

Após homogeneização, os tubos foram colocados em incubação por $24 \mathrm{~h}$, à temperatura de $25, \pm 2 \circ$ C. Após o período de incubação iniciou a quantificação dos conídios. A quantificação da germinação dos conídios foi realizada com auxílio de uma câmara de Neubauer (hemacitômetro). Foram considerados como germinados os conídios com tubos germinativos apresentando comprimento igual ou superior à dimensão do esporo.

\subsection{1 - AVALIAÇÃO DO CRESCIMENTO MICELIAL}

Foi utilizado o meio de cultura BDA, o qual foi preparado, autoclavado e, após o resfriamento deste para temperatura ambiente, foi vertido cerca de $25 \mathrm{ml}$ em placas de 
petri até solidificar o meio. Sobre a superfície do meio foram adicionadas as concentrações de $5 \mu \mathrm{L}, 10 \mu \mathrm{L}, 15 \mu \mathrm{L}, 20 \mu \mathrm{L}$ e $25 \mu \mathrm{L}$ dos óleos de citronela e capim limão para cada isolado do fungo, além de adicionados $20 \mu \mathrm{L}$ do fungicida comercial (sulfato de cobre) para comparação do efeito fungicida em relação ao tratamento com os óleos. Para a preparação da solução com o fungicida adicionou-se 0,1 g em $1 \mathrm{~mL}$ de água destilada (10\%). Já as testemunhas continham apenas o meio de cultura e o fungo, o experimento foi realizado em triplicatas para cada concentração e isolado, ou seja, totalizando vinte uma placas para cada isolado. Em seguida as placas foram riscadas, dividindo-as em quatro quadrantes. Foi depositado um disco de micélio (aproximadamente $1 \mathrm{~cm}$ de diâmetro) do patógeno para o centro de cada placa, após isso, as placas foram vedadas com papel filme e mantidas a 25 , $\pm 2 \stackrel{\circ}{ } \mathrm{C}$ e fotoperíodo de 12 horas.

Ocorreram avaliações diárias, sendo que as medições correspondem à média de duas medidas diametralmente com a utilização de um paquímetro, isto foi realizado até que o micélio da testemunha ocupasse toda a superfície da placa. Então se calculou o índice de velocidade do crescimento micelial (IVCM), determinado pela adaptação da fórmula proposta por Oliveira (1991):

$\operatorname{IVCM}=\Sigma(\mathrm{D}-\mathrm{Da}) / \mathrm{N}$

Sendo:

IVCM= índice de velocidade de crescimento micelial

$D=$ diâmetro médio atual da colônia

Da= diâmetro médio da colônia do dia anterior

$\mathrm{N}=$ número de dias após a inoculação

Em seguida, foi calculado a porcentagem de inibição do crescimento micelial em relação a testemunha e ao fungicida.

Todo o experimento foi conduzido em um delineamento inteiramente casualizado (DIC), com cinco repetições sendo cada parcela constituída por uma placa de Petri. Os valores obtidos nos tratamentos foram submetidos à análise de variância e as médias dos tratamentos comparadas pelo teste Tukey a $5 \%$. Todas as análises foram feitas com auxílio do programa estatístico $R$ (R DEVELOPMENT CORE TEAM, 2011). 


\section{RESULTADOS E DISCUSSÃO}

A seleção das plantas para a extração dos óleos essenciais foram baseados na literatura especializada. Devido à especificidade de algumas espécies de plantas selecionadas (sálvia, tomilho e manjericão), o rendimento do óleo essencial obtido foi abaixo do esperado, sendo necessário maior massa de folhas e a obtenção de mais matrizes, o que aumentaria muito o tempo de realização do experimento. Alguns autores citam as dificuldades de obtenção do óleo essencial para algumas espécies devido à fatores ambientais, morfológicos e metodológicos.

De acordo com Costa e colaboradores (2011), um dos vários fatores que afetam o rendimento do óleo essencial correlaciona-se com os fatores ambientais, tais como a temperatura, intensidade da radiação solar, solo e outros. Ainda de acordo com os autores, também devem ser considerados fatores experimentais, como: a matriz utilizada, a extração realizada pelo destilador, a etapa de extração com solvente e os cuidados com o armazenamento.

Indo nesta mesma direção, Mesquita e colaboradores (2016) cita que as espécies selecionadas para a extração do óleo essencial podem apresentar diferenças em suas estruturas secretoras desse óleo, bem como suas respectivas localizações na planta. Ainda de acordo com eles, a composição química do óleo pode apresentar certa resistência à degradação térmica, gerando então uma grande variabilidade na obtenção e na perda desses metabólitos.

Das plantas citronela e capim-limão obtiveram-se óleos essenciais em quantidades suficientes para o delineamento experimental. O rendimento desses óleos essenciais de foram bem parecidos. Ambos foram calculados em relação à massa fresca, sendo em média de $0,44 \%\left(\mathrm{~mL} . \mathrm{g}^{-1} . \%\right)$ para o capim-limão e de $0,55 \%\left(\mathrm{~mL} . \mathrm{g}^{-1} . \%\right)$ para citronela. A extração do óleo essencial foi realizada em quadruplicata e os resultados apresentados foram a média dos valores obtidos para cada um dos óleos.

Com relação à coloração e o cheiro característico, os óleos essenciais extraídos da citronela apresentaram uma coloração amarela parda e aroma forte peculiar, semelhante ao 
óleo comercial. Já para o capim-limão, a coloração foi mais clara, também com aroma característico da planta.

Quanto à atividade do óleo essencial contra o fungo Colletotrichum acutatum houve redução do crescimento micelial dos dois isolados (645 e 754) em função das alíquotas crescentes do óleo estudado (Figura 01 e 02). Observa-se nos resultados obtidos, que o óleo essencial de capim limão foi mais eficiente na redução do crescimento micelial quando comparado com o de citronela e estes com a testemunha.

Os resultados corroboram com os achados da pesquisa de Lorenzetti e colaboradores (2011), quando em seus achados os óleos de capim limão e de canela mostram-se ser mais efetivos em seus isolados resistentes quando comparados com outros óleos essenciais utilizados no experimento, dentre eles os de citronela.

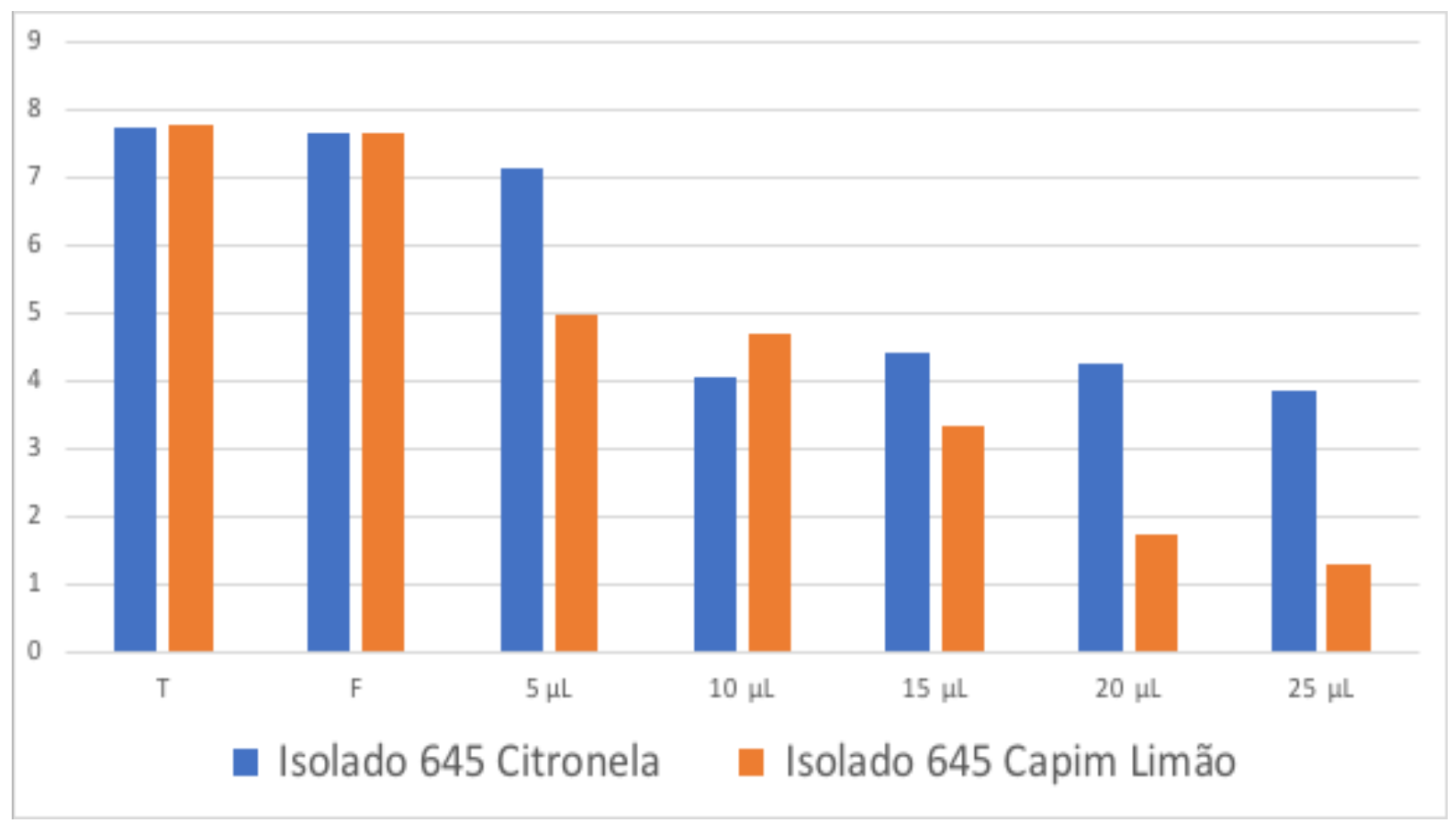

Figura 01. Crescimento micelial $(\mathrm{cm})$ "in vitro" do isolado 645 de $C$. acutatum submetido a diferentes alíquotas (T, F, $5 \mu \mathrm{L}, 10 \mu \mathrm{L}, 15 \mu \mathrm{L}, 20 \mu \mathrm{L}$ e $25 \mu \mathrm{L})$ do óleo essencial de citronela e capim-limão. $T=$ testemunha (alíquota sem óleo essencial) e $F=$ fungicida comercial vendido em comércios para jardinagem ornamental - Sulfato de cobre. 


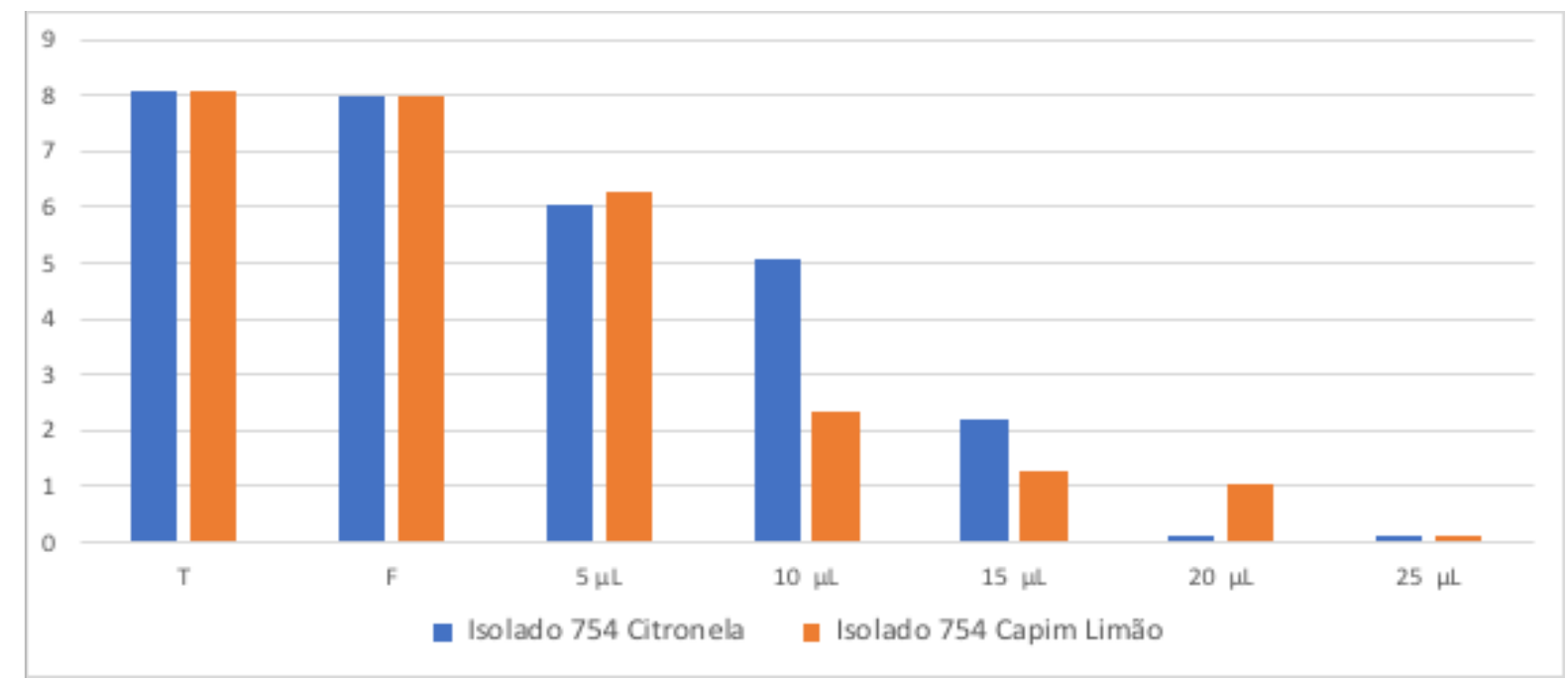

Figura 02. Crescimento micelial $(\mathrm{cm})$ "in vitro" do isolado 754 de $C$. acutatum submetido a diferentes alíquotas (T, F, $5 \mu \mathrm{L}, 10 \mu \mathrm{L}, 15 \mu \mathrm{L}, 20 \mu \mathrm{L}$ e $25 \mu \mathrm{L})$ do óleo essencial de citronela e capim-limão. $T=$ testemunha (alíquota sem óleo essencial) e $F=$ fungicida comercial vendido em comércios para jardinagem ornamental - Sulfato de cobre.

Sobre a inibição da germinação de conídios e de formação dos apressórios, o óleo essencial de capim limão se mostrou mais eficiente que a citronela. No tratamento a partir de $15 \mu \mathrm{L}$ de óleo essencial capim limão, ocorreu uma taxa de inibição de $60 \%$ da germinação de conídios e de formação dos apressórios, chegando a mais de $90 \%$ quando comparados com os tratamentos acima de $20 \mu \mathrm{L}$ de óleo essencial e a testemunha. O sulfato de cobre, fungicida comercial, obteve taxa de inibição de $65 \%$ da germinação de conídios e de formação dos apressórios.

Resultados semelhantes foram obtidos por Cruz e colaboradores (2015), que observaram inibição de modo crescente em seus isolados utilizando o óleo de citronela. Eles verificaram uma redução de mais de $90 \%$ de germinação em alíquotas com $15 \mu \mathrm{L}$ de óleo, chegando a praticamente $99 \%$ na alíquota com $30 \mu \mathrm{L}$.

Ainda corroborando com Cruz e colaboradores (2015), os nossos achados (figura 03 e 04), de óleo essencial de citronela se mostrou eficiente na redução do crescimento micelial contra três isolados do fungo fitopatógeno Fusarium solani e em relação a germinação dos conídios, houve redução em mais de $90 \%$ na menor concentração (Figura 05). Estes resultados corroboram aos obtidos no presente trabalho. 


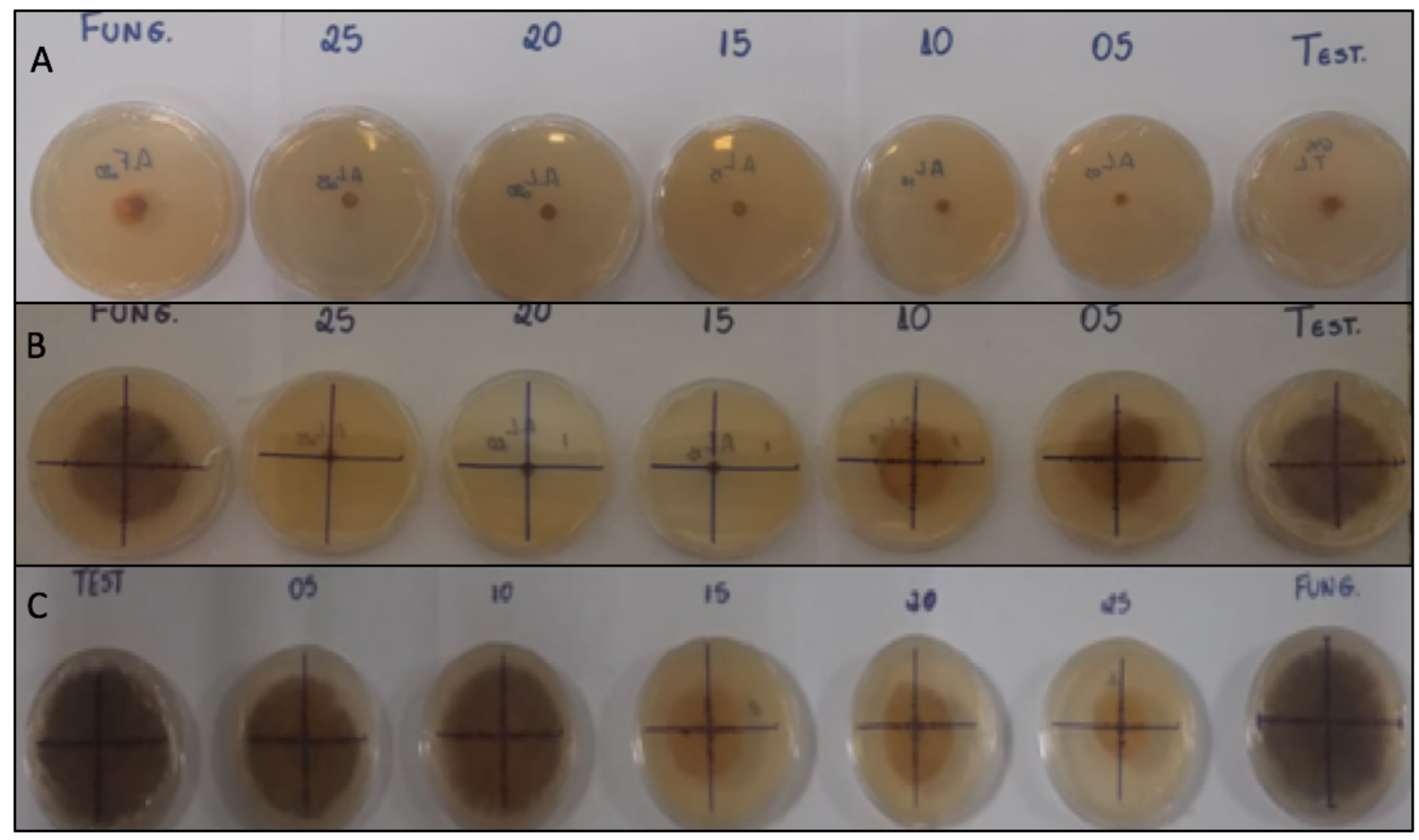

Figura 03: Fotos do crescimento micelial obtidas no (A) 1ㅇ , (B) 7으 e (C) 15 dias após 24h da inoculação com o isolado 645 e o óleo essencial capim-limão. Fung= placa com fungicida; 05 a 25 = quantidade em $\mu \mathrm{L}$ de óleo essencial usada em cada placa e Test = testemunha, placa de Petri apenas com o inóculo.

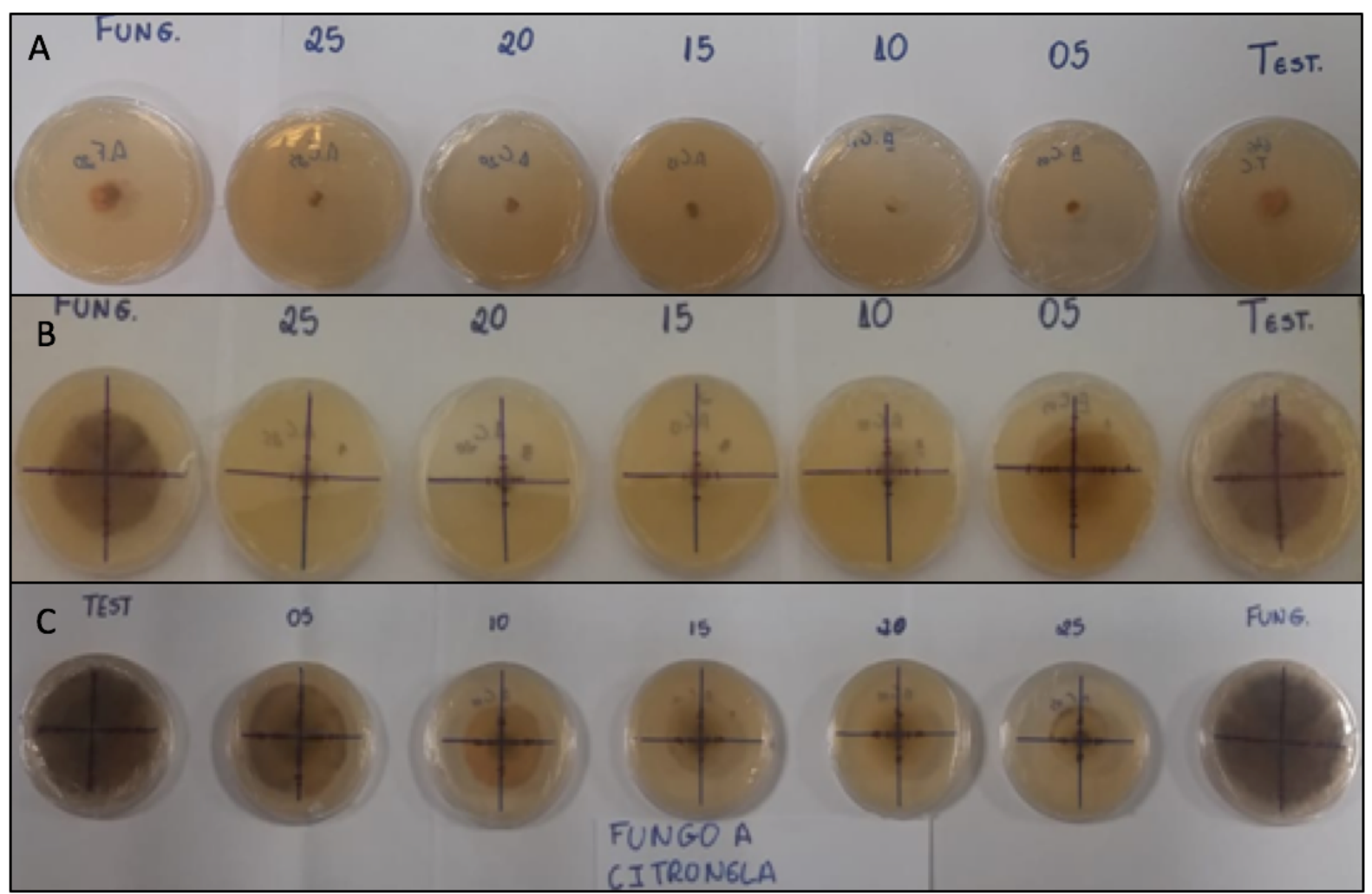

Figura 04: Fotos do crescimento micelial obtidas no (A) 1으 , (B) 70 e (C) 15 으 dias após 24h da inoculação com o isolado 645 e o óleo essencial citronela. Fung= placa com fungicida; 05 a 
25 = quantidade em $\mu \mathrm{L}$ de óleo essencial usada em cada placa e Test = testemunha, placa de Petri apenas com o inóculo.

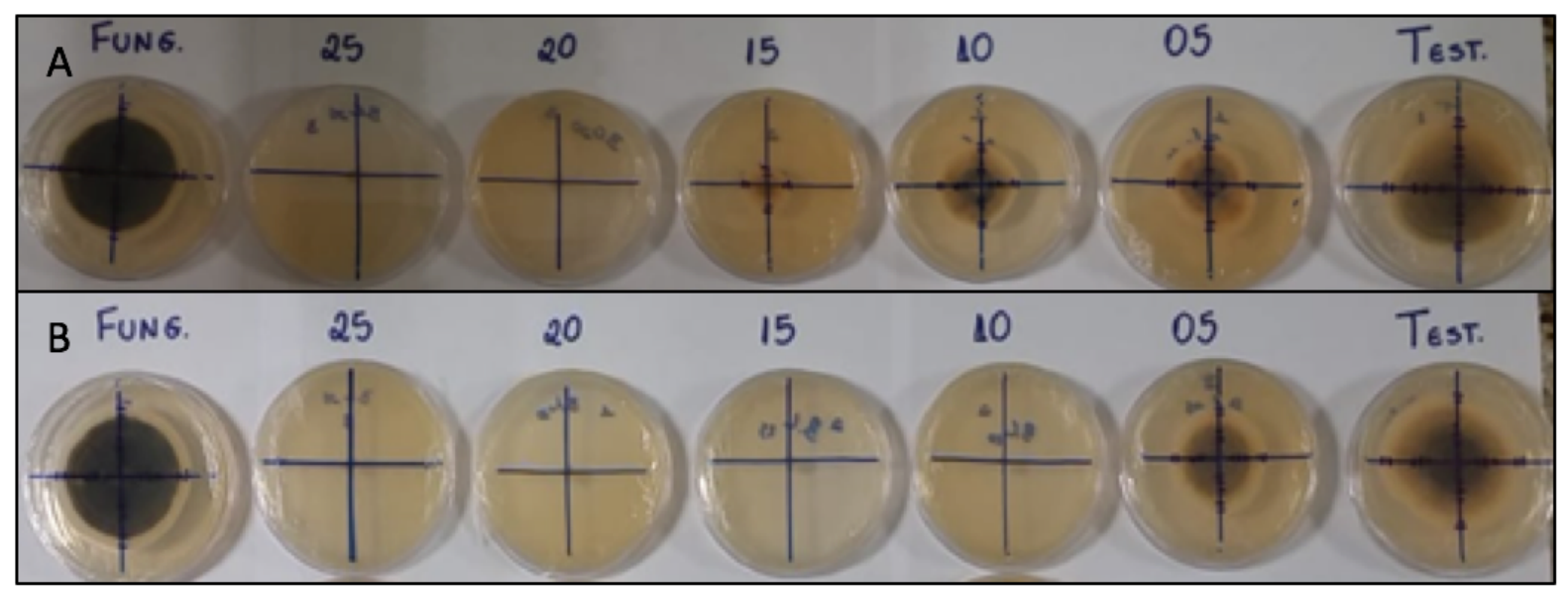

Figura 05: Fotos do crescimento micelial obtidas nos 15 dias após $24 \mathrm{~h}$ da inoculação com os isolados 754 e em A) óleo essencial capim-limão e em B) óleo essencial citronela. Fung= placa com fungicida; 05 a 25 = quantidade em $\mu \mathrm{L}$ de óleo essencial usada em cada placa e Test $=$ testemunha, placa de Petri apenas com o inóculo.

\section{CONCLUSÃO}

Assim sendo os óleos essenciais de $C$. winterianus e $C$. citratus se mostraram eficientes tanto na avaliação do crescimento micelial quanto na germinação de conídios, porém o efeito inibidor do óleo de Citronela se mostrou mais promissor no tratamento do isolado Coll 645 (fungo A) na avaliação do crescimento micelial. Se faz necessário maiores estudos para se obter a concentração de óleo essencial ideal que reduza $100 \%$ a atividade do patógeno, conclui-se então que é preciso ser feito mais testes com esses dois óleos em concentrações maiores que $25 \mu \mathrm{L}$ para se obter melhores resultados.

Dessa forma, observa-se que os óleos essenciais apresentam uma nova alternativa para o manejo de doenças relacionadas à fungos.

A identificação de componentes presentes nos óleos essenciais que exercem efeito no controle de doenças, torna-se uma ferramenta importantíssima para a indústria química quanto ao desenvolvimento de novos produtos.

No mesmo rumo temos o avanço da agricultura orgânica, aliadas ao mercado consumidor mais consciente e exigente por produtos desenvolvidos em práticas agrícolas 
menos agressivas, o uso de óleos essenciais podem ser uma boa escolha, pois além de aliar as características de controle de doenças, é de baixa toxicidade e fácil de manusear e aplicar.

\section{REFERÊNCIAS}

BRASIL. SEAB - Secretaria de Estado da Agricultura e do Abastecimento DERALDepartamento de Economia Rural. 2015.

COSTA, A.R.T.; AMARAL, M.F.Z.J.; MARTINS, P.M.; PAULA, J.A.M.; FIUZA, T.S.; RESVENZOL, L.M.F.; PAULA, J.R.; BARA, M.T.F. Ação do óleo essencial de Syzygiumaromaticum (L.) Merr. \& L.M. Perry sobre as hifas de alguns fungos fitopatogênicos. Revista Brasileira de Plantas Medicinais. v.13, n.2, p. 240245, 2011.

COSTA, O. B. ; MENEZZI, C. H. S. ; RESCK, I. S. . Rendimento do óleo essencial de duas espécies do cerrado: Myracrodruon urundeuva (Allemão) e Blepharocalyx salicifolius (kunt) o. berg em diferentes horários de coleta. In: V Congreso Forestal Latinoamericano, 2011, Lima. El futuro del mundo depende de los bosques. Lima: UNALM, 2011. v. 1. p. 1-8.

CRUZ, T.P.; ALVES, F.R; MENDONÇA, R.F.; COSTA, A.V.; JESUS JUNIOR, W. C.; PINHEIRO, P.F. e MARINS, A.K. Atividade fungicida do óleo essencial de Cymbopogonwinterianusjowit (citronela) contra Fusariumsolani. Biosci. J., Uberlandia, v. 31, n. 1, p. 1-8, Jan./Feb. 2015.

FRANCO, D.A.; BETTIOL, W. Controle de Penicillium digitatum em pós-colheita de citros com produtos alternativos. Fitopatologia Brasileira, Brasília, v.25, p.602-606, 2000.

GILLES, M.; ZHAO, J.; AN, M.; AGBOOLA, S. Chemical composition and antimicrobial properties of essential oils of three Australian Eucalyptus species. Food Chemistry. v.119, p.731-737, 2010.

GOMES, K. B. P; OLIVEIRA, G. H. H; CARVALHO, J. P; CAVALCANTE, D. F. S; VILLA-REAL, M. E. Diagnóstico da cadeia produtiva do morango dos agricultores familiares do Distrito Federal. Revista EIXO, Brasília - DF, v.2 n.2, 2013. 
HENZ, G. P. Desafios enfrentados por agricultores familiares na produção de morango no Distrito Federal. Horticultura Brasileira, v. 28, n. 3, p. 260-265, 2010.

KOSOSKI, R. M.; FURLANETTO, C.; TOMITA, C. K. e CAFE FILHO, A. C.. Efeito de fungicidas em Colletotrichum acutatum e controle da antracnose do morangueiro. Fitopatol. bras. [online]. 2001, vol.26, n.3. pp.662-666.

MAIA, T.F.; DONATO, A.; FRAGA, M. E. Atividade Antifúngica de Óleos Essenciais de plantas. Revista Brasileira de Produtos Agroindustriais. Campina Grande, v.17, n.1, p.105-116, 2015.

MATTOS SH; CHAVES CMC; INNECCO R; CRUZ GF. 2000. Estudos sobre a época de corte e espaçamento de alecrim-pimenta. Horticultura Brasileira 18: 996-997.

MESQUITA, T.J.B; RIBAS, B.D; ALBUQUERQUE, P.M.; DUVOISIN JUNIOR, S. Influência da temperatura e tempo de secagem na obtenção de óleo essencial de citronela (Cymbopogon winteranius).In: Anais do Congresso Brasileiro de Engenharia Química, 2016, . Resumos...Campinas, GALOÁ,

MORAIS L.A.S, CASTANHA, R.F. 2012. Composição química do óleo essencial de manjericão naturalmente submetido ao ataque de cochonilhas. Horticultura Brasileira 30: S2178-S2182.

MORAIS, L; GONÇALVES, G.; BETTIOL, W. Óleos essenciais no controle de doenças de plantas. Revisão Anual de Patologia de Plantas- Volume 17, 2009.

OLIVEIRA, J. A. Efeito do tratamento fungicida em sementes no controle de tombamento de plântulas de pepino (Cucumis sativas L.) e pimentão (Capsicumannanum L.). 1991. 111 f. Dissertação (Mestrado em Fitossanidade) - Escola Superior de Agricultura de Lavras, Lavras, 1999.

PIEROZAN, M. K. et al.Caracterização química e atividade antimicrobiana de óleos essenciais de espécies da Salvia L.Ciênc. Tecnol. Aliment. Vol.29 no.4 Campinas dezembro de 2009.Disponível

em: hhttp://www.scielo.br/scielo.php?script=sci arttext\&pid=S010120612009000400010\&la

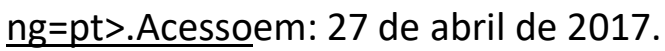


ROCHA, R. P.et al. Influência do processo de secagem sobre os principais componentes químicos do óleo essencial de tomilho. Rev. Ceres. Vol.59, no. 5, Viçosa Sept./Oct. 2012. Disponível

em: http:<//www.scielo.br/scielo.php?script=sci arttext\&pid=S0034737X2012000500021\&lang= pt>.Acessoem: 27 de abril de 2017.

SCHWAN-ESTRADA, K. R. F., et al. Uso de extratos vegetais no controle de fungos fitopatogênicos. Seminário de Atualidades em Proteção Florestal. 2000.

SILVA, M. R. L. et al.Antracnose no café: doença emergente. Cultivar grandes culturas. n. 177. ISSN. 1516-358X. Fev. 2014. Disponível em: http://www.grupocultivar.com.br/artigos/doenca-emergente. Acesso em: 01 de maio de 2017.

SIMÕES, CMO; SPITZER, V. Óleos voláteis. In: Simões, CMO et al. Farmacognosia: da planta ao medicamento. Porto Alegre/Florianópolis: Ed. Universidade/UFRGS / Ed. Da UFSC, p. 387 $-415.1999$.

SIMON, N.; MENEGUZZO, A; CALGARO, A. Doenças causadas por fungos e bactérias. In: SANHUEZA, R.M.V.; HOFFMANN, H.; ANTUNES, L.E.C.; FREIRE, J. M. Sistema de produção de morango para mesa na região da serra gaúcha e encosta superior do Nordeste. Bento Goncalves: Embrapa Uva e Vinho. (Sistema de Produção, 6). Disponível em: <https://sistemasdeproducao.cnptia.embrapa.br/>. Acesso em: 26 de Abril de 2017.

SOUSA, R.M.S; SERRA, I.M.R.S; MELO, T.A. Efeito de óleos essenciais como alternativa no controle de Colletotrichum gloeosporioides, em pimenta. Summa Phytopathologica, v.38, n.1, p.42-47, 2012.

TANAKA, M. A. S.; BETTI, J. A.; KIMATI, H. Doencas do morangueiro. In: KIMATI, H.; AMORIM, L.; REZENDE, J. A. M.; BeRgaMin FILHO, A.; CAMARgO, L. E. A. (Ed.) Manual de Fitopatologia: doenças das plantas cultivadas. 4. Ed. São Paulo: Agronômica Ceres. 2005. v.2, p. 489-499.

TREICHEL, M. et al. Anuário brasileiro da fruticultura 2016. Santa Cruz do Sul: Editora Gazeta Santa Cruz,. 88p.: 2016. Disponível em: 
<http://www.grupogaz.com.br/tratadas/eo edicao/4/2016/04/20160414 0d40a2e2a/pdf/5 149 2016fruticultura.pdf> Acesso em 01 de maio de 2017.

VIGNOLO, G., REISSER JUNIOR, C.; ANTUNES, L. E. C.; ALDRIGHI, M.; Panorama do cultivo dos morangos no Brasil. Campo e Negócio - Hortifruti. 2014. Disponível em <https://ainfo.cnptia.embrapa.br/digital/bitstream/item/116016/1/CampoNegocio-DEZ2014-Panorama.pdf> Acesso em 02 de maio de 2017.

VILLAVERDE, J. M. et al. Efeitos do óleo essencial do capim-limão (Cymbopogon citratus Stapf) sobre células humanas de melanoma (SK-MEL 147) e queratinócitos (HaCaT) Biosaúde, Londrina, v. 15, n. 1, 2013.

WOLFFENBÜTTEL, A.N. Óleos Essenciais, 2007. Disponível em: http://www.oleoessencial.com.br/artigo_Adriana.pdf. Acesso em: 27 de abril de 2017. 